\title{
The Cognitive Cost of Being a Twin: Two Whole-Population Surveys
}

\author{
Ian J. Deary,' Alison Pattie,' Valerie Wilson, ${ }^{2}$ and Lawrence J. Whalley ${ }^{3}$ \\ 'Department of Psychology, University of Edinburgh, Edinburgh, United Kingdom \\ ${ }^{2}$ SCRE Centre, Faculty of Education, University of Glasgow, Glasgow, United Kingdom \\ ${ }^{3}$ Department of Mental Health, University of Aberdeen, Aberdeen, United Kingdom
}

$\mathrm{D}$ o twins have a lower mean IQ score than singletons? Previous studies have not examined whole populations and are likely to be biased. Twin data from two whole-population surveys of IQ at age 11 years were examined: the Scottish Mental Surveys of 1932 and 1947. Additional variables from childhood were examined as possible mediating effects. There were 1080 twins from the 1932 survey, and 949 from the 1947 survey. In both surveys twins scored lower on the Moray House Test of verbal reasoning, equivalent to a deficit of about 5 IQ points. In the Scottish Mental Survey of 1947 the whole-population group of twins was compared in detail with a representative population sample. The same mental ability difference of about $5 \mathrm{IQ}$ points was found, and was not accounted for by father's occupation, overcrowding in the childhood home, childhood height, school attendance or the number of people in the family.

Do twins have, on average, lower cognitive ability test scores than singletons? The question has been posed several times before and has, as yet, no definitive answer. As recently as 2000, Posthuma et al. (2000) stated that, 'significant disadvantages of twins in comparison with singletons seem to be implied rather than observed'. Even if mean differences are found in cognitive test scores between twins and singletons, Posthuma et al. identified two further obstacles before a firm conclusion may be reached. These two chronic limitations of previous studies, even of large samples (e.g., Breland, 1974), are that selection bias might occur in the sampling of twin and singleton samples, and any twin-singleton differences in cognition might be due to a priori differences in social background. To overcome these limitations, the present study examined two wholepopulation surveys of mental ability, one of which also has information on social background.

A summary of some previous studies does suggest a possible lower mean for mental ability test scores and possibly school achievement in twins. Among the United States's National Merit Scholarship participants who were teenagers, twins scored just under one third of a standard deviation lower than the population mean in a test that combined English, mathematics, social studies, natural science and word usage (Breland, 1974). One study linked the birthweights of all live births in Birmingham, United Kingdom, between 1950 and 1954 to verbal reasoning scores at the age of 11 years. It was, therefore, probably unbiased. It found twins to be between 4 and 5 IQ points $(S D=15)$ lower than singletons (Record et al., 1970). The Collaborative Perinatal Project of the United States found that, at the ages of 8 months (Bayley mental scores), 4 years (Stanford-Binet) and 7 years (Wechsler Intelligence Scale for Children), twins had lower scores of about one third to one half of a standard deviation (Myrianthopoulos et al., 1976). Twins came from families with similar socioeconomic backgrounds to the whole population. However, the overall number of twins was not large and there was considerable attrition by the age of 7 years. Twins, especially boys, in the Australian Survey of School Performance had lower scores on a word knowledge test and lower achievement in literacy and numeracy at age 10 and 14 years (Hay et al., 1984). A Stockholm-based study found that twins had relatively slight mental test score differences to singletons (Alin Akerman \& Fischbein, 1991). Twin boys were slightly lower on verbal ability and twin girls were slightly lower on verbal and numerical ability in grade 6 , but there were few differences in school marks. At the age of 18 years, twin boys had only very slightly lower reasoning differences compared with singletons, typically less than a quarter of a standard deviation. In a study that compared adult twins with their nontwin siblings on a subtest from the Wechsler Adult Intelligence Scale-III, Posthuma et al. (2000) found no cognitive decrement among twins. Other studies are simply too small to add substantively to the debate (Nathan \& Guttman, 1984).

Received 13 April, 2005; accepted 24 May, 2005.

Address for correspondence: Ian J. Deary, Department of Psychology, University of Edinburgh, 7 George Square, Edinburgh EH8 9JZ, UK. E-mail:I.Deary@ed.ac.uk 
In the present study we examine whether twins differ in mean cognitive ability test scores in two whole-population studies of mental ability: the Scottish Mental Surveys of 1932 and 1947 (SMS 1932, and SMS1947, respectively; Deary et al., 2004; Scottish Council for Research in Education, 1933, 1949). Both surveys were administered by the Scottish Council for Research in Education (SCRE). SCRE retained the data from the surveys and gave permission for their use in the present report. Being whole-population surveys, the subjects are unselected. In the SMS1932 and SMS1947, almost all children attending school in Scotland and born in the years 1921 and 1936 respectively sat the same version of the Moray House Test (MHT), on June 1, 1932 and June 4, 1947, respectively. The 1947 survey has social background information on the families of the twins and of a representative sample, and so we can ask if this factor accounts for any mental ability differences between twins and singletons. Twin-singleton differences on the MHT were reported as a brief report (Mehrotra \& Maxwell, 1949) and a more detailed chapter in one of the monographs that arose from the SMS1947 (Scottish Council for Research in Education, 1953). They are rarely referred to in more recent investigations of this question. These alreadyreported findings are summarized in the present Results section.

\section{$\overline{\text { Method }}$ \\ Moray House Test}

The mental test used in both the SMS1932 and SMS1947 was a version of the MHT No. 12. Its items are described elsewhere (Deary et al., 2000; Scottish Council for Research in Education, 1949). It is a group-administered test of mental ability, with a time limit of 45 minutes. It has a maximum score of 76 . The content is principally verbal reasoning, but it has items with other content, such as numerical and spatial items. The MHT used in the surveys has high lifelong stability (Deary et al., 2000, 2004), and correlates highly with well-recognized tests of general mental ability, namely, the Stanford-Binet at the age of 11 (Scottish Council for Research in Education, 1933) and Raven's Standard Progressive Matrices in old age (Deary et al., 2004).

\section{Scottish Mental Survey 1932 (SMS1932)}

Whole population. The SMS1932 is fully described in SCRE's 1933 monograph and summarized in a recent overview (Deary et al., 2004). Briefly, 87,498 Scottish schoolchildren who were born in 1921 took the MHT. The handwritten records of the SMS1932 were computerized, as described previously (Hart et al., 2003). The ledgers from the counties Fife, Wigtown and Angus were missing. This computerized resource was used as the whole population with which the twins were compared.
Twins. Twins were not specially identified in the original SMS1932 data ledgers. Therefore, the following procedure was devised to identify probable twin pairs from the SMS1932 computerized resource. People who had the same surname, appeared in the same school, and had the same date of birth were identified as twins.

\section{Scottish Mental Survey 1947 (SMS1947)}

Whole population. The SMS1947 is fully described in monographs (Maxwell, 1961; Scottish Council for Research in Education, 1949, 1953) and summarized in a recent overview (Deary et al., 2004). Briefly, 78,805 Scottish schoolchildren who were born in 1936 took the MHT. The SMS1947 exists in confidential paper records with SCRE. To date there is no validated computerized version. Twin-general population comparisons were based upon the original monograph reports from the SMS1947 (Scottish Council for Research in Education, 1953) and effect sizes were computed. This monograph has more detail than the earlier journal article report on these twins (Mehrotra \& Maxwell, 1949).

Twins. Twins born in 1936 and who took part in the SMS1947 provided data in addition to completing the MHT. Data were collected on father's occupation, number of people and rooms in the house, actual and possible school attendance, height, and number of people in the family. Father's occupation was newly coded for the present report into the five-category system used at the time based on the Office of Population and Census Studies. The number of people in the house was divided by the number of rooms to give an occupancy index. Possible school attendance was divided by actual attendance to give percentage attendance. Records exist for 1034 of the 1050 $(98.5 \%)$ twins discussed in the SCRE's 1953 monograph, 949 of whom had a MHT score, compared with $974(97.4 \%)$ in the SCRE report.

The 6-day sample. The 6-day sample of the SMS1947 represents people born on the first day of the evennumbered months. It is, therefore, representative of the whole population. There are 1208 subjects, 1098 of whom have an MHT score. The data collected on the 6-day sample has been described elsewhere (Deary et al., 2004; Maxwell, 1961). The 6-day sample provided the same variables as collected on the twins. For the present report, the 6-day sample was used as a representative population sample with which to compare the twins. In the original SCRE report the 6-day sample was found to be representative of the whole SMS1947 population in terms of age, sex, MHT score, father's occupation, family size and home occupancy (MacPherson, 1958, pp. 4-9). Members of twin pairs (14 individuals) were removed from the 6-day sample.

\section{Results}

Scottish Mental Survey 1932

There were 87,498 people with MHT scores in the SMS1932 (Scottish Council for Research in 

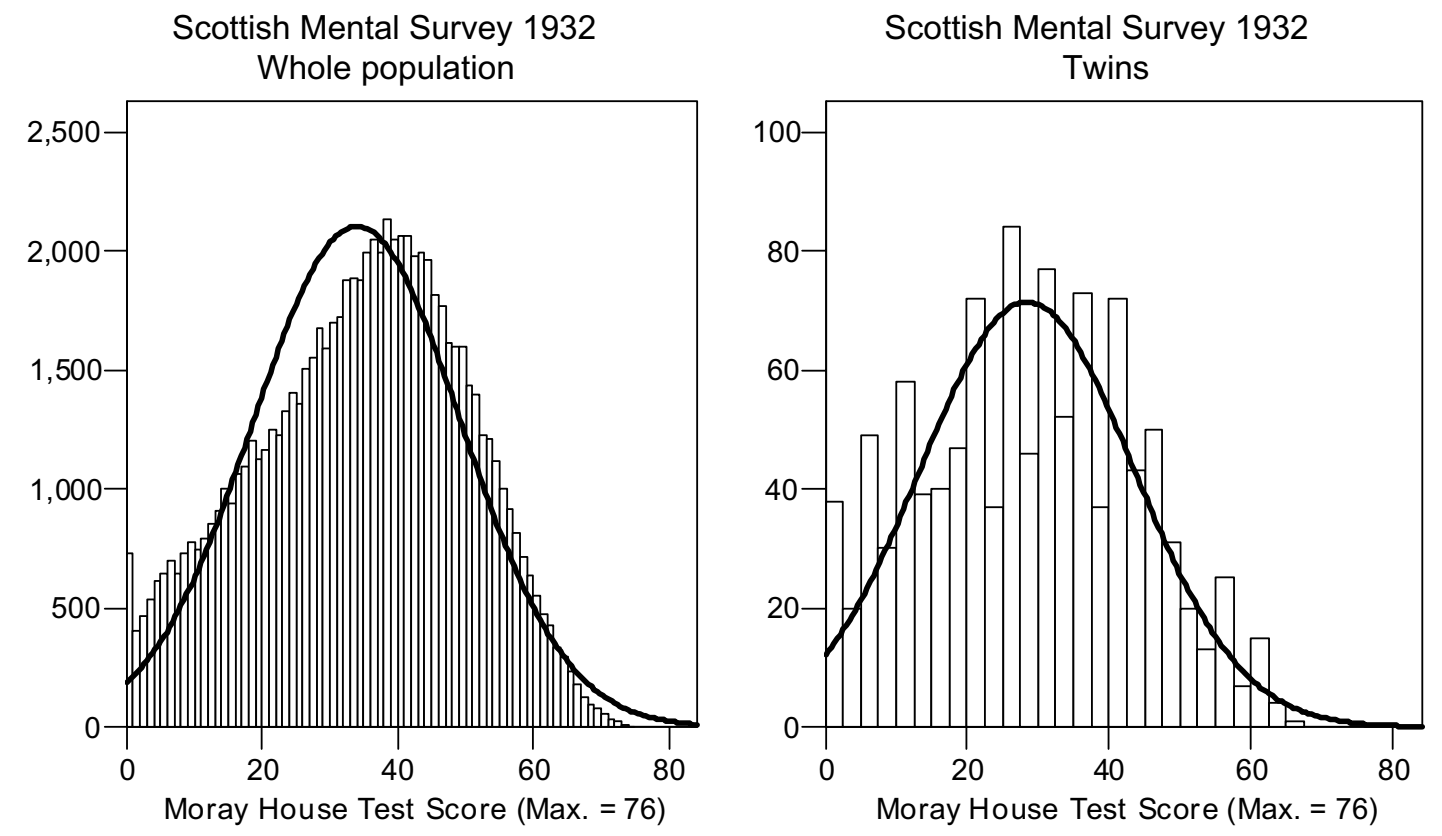

Figure 1

Distributions (with normal curve added) of Moray House Test (MHT) scores for the whole population (left panel) and twins (right panel) in the Scottish Mental Survey 1932.

Education, 1933). The now-remaining ledgers of the SMS1932 contain records of 86,520 individuals of whom 81,140 (93.78\%; 41,019 boys, 40,121 girls) have MHT scores entered. Therefore, by extrapolation, 87,498 represent a background population of about 93,300. Among the 86,520, 1146 twins were identified, which equates to about 1222 in the 11year-old background population in 1932. Twins make up therefore about $1.32 \%$ of the population, similar to the $1.48 \%$ found in the SMS1947 (i.e., 1050 out of $[1050+69,831])$. The Registrar General for Scotland Annual Report for 1921 returned 1596 (3192 individuals) live twin-pair births in addition to eight sets of triplets. Therefore, there is an ascertainment of around $38.3 \%$. This compares with about $50 \%$ for the SMS1947 (Scottish Council for Research in Education, 1953, p. 135).

The mean (SD) MHT score of this SMS1932 whole population (from the computerized resource; $N=81,140)$ is 33.9 ( $S D=15.4$; Figure 1$)$. The mean for boys was $34.05(S D=15.8)$, and for girls was $33.88(S D=14.9)$. There were 1146 individuals identified as twins (573 pairs), of whom $1080(94.24 \%)$ had a MHT score. The mean (SD) MHT score of the twins is $28.5(S D=15.1$; Figure 1$)$. The mean for male twins was $28.45(S D=15.3)$, and for girls 28.46 $(S D=14.9)$. The twin-whole population difference is 5.4 MHT score points, Cohen's $d=0.36$, and effect size $r=.18$. The differences between twins and the whole population for boys and girls are 5.6 and 5.4 MHT points, respectively.

\section{Scottish Mental Survey 1947 (SMS1947)}

Whole population. Some analyses were carried out on the twins from the SMS1947 and reported in a monograph (Scottish Council for Research in Education, 1953, pp. 135-157). This paragraph alone summarizes these previously reported findings. They recorded 1050 twins, 974 of whom (469 boys, 505 girls) had MHT scores. The mean MHT score for all twins was $31.92(S D=16.52 ; N=974)$ and for all nontwins was $36.75(S D=16.03 ; N=69,831)$, a difference of 4.83 points (Scottish Council for Research in Education, 1953, p. 137). The difference of 4.83 points corresponds to a Cohen's $d=0.30$, and effect size $r=.15$ (calculations performed for this report). The difference for boys was 5.55 and for girls was 4.26. The mean and distribution of ages for twins and nontwins was very similar. The difference was not caused by a 'bunching' (Scottish Council for Research in Education, 1953, p. 138) of the twins' scores at the lower end of the distribution. A series of simple investigations of some possible causal factors were then carried out. In these, twins' scores were compared with those of a representative sample by listing the scores of both groups by level of the possible explanatory variable and applying $t$ tests. There was no difference in family size, known to be associated with MHT score, between twins and nontwins. Mothers of twins tended to be older, but maternal age was not the cause of the twin versus nontwin MHT score difference. Home overcrowding was not the cause, and nor was the occupational class of the father. The analyses conducted on the SMS hereinafter are based on newly transcribed and collated data. 


\section{Table 1}

Social Class of Fathers of Twins and 6-Day Sample Participants of the Scottish Mental Survey 1947

\begin{tabular}{lcc}
\hline $\begin{array}{l}\text { OPCS occupational } \\
\text { class }^{*}\end{array}$ & Twins & 6-day sample \\
\hline 1 & $34(3.3)$ & $30(2.5)$ \\
2 & $140(13.5)$ & $119(10.0)$ \\
3 & $524(50.7)$ & $617(51.7)$ \\
4 & $188(18.2)$ & $202(16.9)$ \\
5 & $134(13.0)$ & $206(17.3)$ \\
\hline
\end{tabular}

Note: $N(\%)$

OPCS $=$ Office of Population and Census Studies

Lower numbers indicate more professional occupations, higher numbers more manual occupations.

Comparison with the 6-day sample. Among the twins there were $499(48.3 \%)$ boys and $535(51.7 \%)$ girls. In the 6-day sample there were $585(49 \%)$ boys and 609 $(51.0 \%)$ girls. These proportions did not differ significantly $\left(\chi^{2}=0.12, d f=1, p=.73\right)$. The fathers' occupational social classes for twins and 6-day sample subjects are shown in Table 1. The proportions in each occupational class were similar, though there was a significant difference, with twins having fathers in more professional occupations $\left(\chi^{2}=14.54, d f=4, p=.006\right)$.

The mean MHT score for twins was 32.2 $(S D=16.3)$ and for 6-day sample subjects was 37.5 (15.7), a difference in the means of 5.3 points $(t=7.48, p<.001$, Cohen's $d=0.33$, effect size $r=.16$; Table 2; Figure 2). The standard deviations did not differ significantly (Levene's test; $F=2.36$, $p=.12$ ). Twins were not significantly different in age, home occupancy index, or school attendance, though there was a trend towards their attending more days at school ( $p=.057$; Table 2$)$. Twins were significantly shorter, and had more people in their immediate family (Table 2). Father's social class, age at MHT testing, home occupancy index, school attendance, height and number in immediate family were significantly correlated with MHT score in the whole sample and in the twins and 6-day sample separately (Table 2). Scores from twin pairs are nonindependent. Therefore, the correlations for twins were rerun by randomly selecting one member from each pair. These correlations were very similar to the coefficients using the whole twin sample (results not shown but available from the authors).

Figures 3 (males) and 4 (females) show the MHT scores for the twins and the 6-day sample, divided by sex and father's occupational social class. In all cases the twins scored lower than the 6-day sample, and there is a trend for subjects with fathers from more professional occupations to score better. There is no obvious interaction between group (twins vs. 6-day sample) and occupational class.

A general linear model was run with the MHT score as the outcome variable, group (twin or 6-day sample), sex and father's occupational social class as fixed effects, and age at SMS1947 testing, home occupancy index, percentage school attendance, height and number in family as covariates. There were no two- or three-way interactions among the fixed effects and these were not included in the final model. The contribution of the fixed effects and covariates, all of which were significant, to MHT score are shown in Table 3.

Table 2

Twins Compared with 6-day Sample Subjects

\begin{tabular}{|c|c|c|c|c|c|c|}
\hline & Twins & 6-day sample & $\begin{array}{c}p \text { value } \\
\text { for difference }\end{array}$ & $\begin{array}{l}\text { Correlation }(p) \\
\text { with MHT score: } \\
\text { all subjects }\end{array}$ & $\begin{array}{c}\text { Correlation }(p) \\
\text { with MHT score: } \\
\text { twins }\end{array}$ & $\begin{array}{c}\text { Correlation }(p) \\
\text { with MHT score: } \\
\text { 6-day sample }\end{array}$ \\
\hline MHT score & $32.2(949 ; 16.3)$ & $37.5(1098 ; 15.7)$ & $<.001$ & & & \\
\hline $\begin{array}{l}\text { Father's OPCS } \\
\text { occupational class* }\end{array}$ & See Table 1 & See Table 1 & & $-.22(<.001)$ & $-.24(<.001)$ & $-.29(<.001)$ \\
\hline $\begin{array}{l}\text { Sext } \\
\text { Age (Years) }\end{array}$ & $\begin{array}{r}\text { See text } \\
10.08(1034 ; 0.28)\end{array}$ & $\begin{array}{r}\text { See text } \\
10.06(1194 ; 0.27)\end{array}$ & $=.37$ & $\begin{array}{l}.04(=.058) \\
.20(<.001)\end{array}$ & $\begin{array}{l}.08(=.019) \\
.21(<.001)\end{array}$ & $\begin{array}{l}.01(=.64) \\
.18(<.001)\end{array}$ \\
\hline Home occupancy & $0.62(1026 ; 0.34)$ & $0.63(1141 ; 0.36)$ & $=.54$ & $.29(<.001)$ & $.33(<.001)$ & $.25(<.001)$ \\
\hline $\begin{array}{l}\text { School attendance } \\
\text { (per cent) }\end{array}$ & $91.9(1023 ; 9.7)$ & $91.1(1153 ; 9.6)$ & $=.057$ & $.13(<.001)$ & $.14(<.001)$ & $.13(<.001)$ \\
\hline Height (inches) & $53.6(1009 ; 2.7)$ & $54.1(1151 ; 2.9)$ & $<.001$ & $.30(<.001)$ & $.26(<.001)$ & $.31(<.001)$ \\
\hline Number in family & $4.7(1030 ; 2.3)$ & $3.8(1190 ; 2.4)$ & $<.001$ & $-.32(<.001)$ & $-.31(<.001)$ & $-.29(<.001)$ \\
\hline
\end{tabular}

Note: Values are Mean $(N ; S D)$.

OPCS = Office of Population and Census Studies

Correlations (Pearson unless indicated otherwise) between Moray House Test (MHT) scores and fixed effects and covariates.

*Spearman correlation. $†$ Point biserial correlation. 

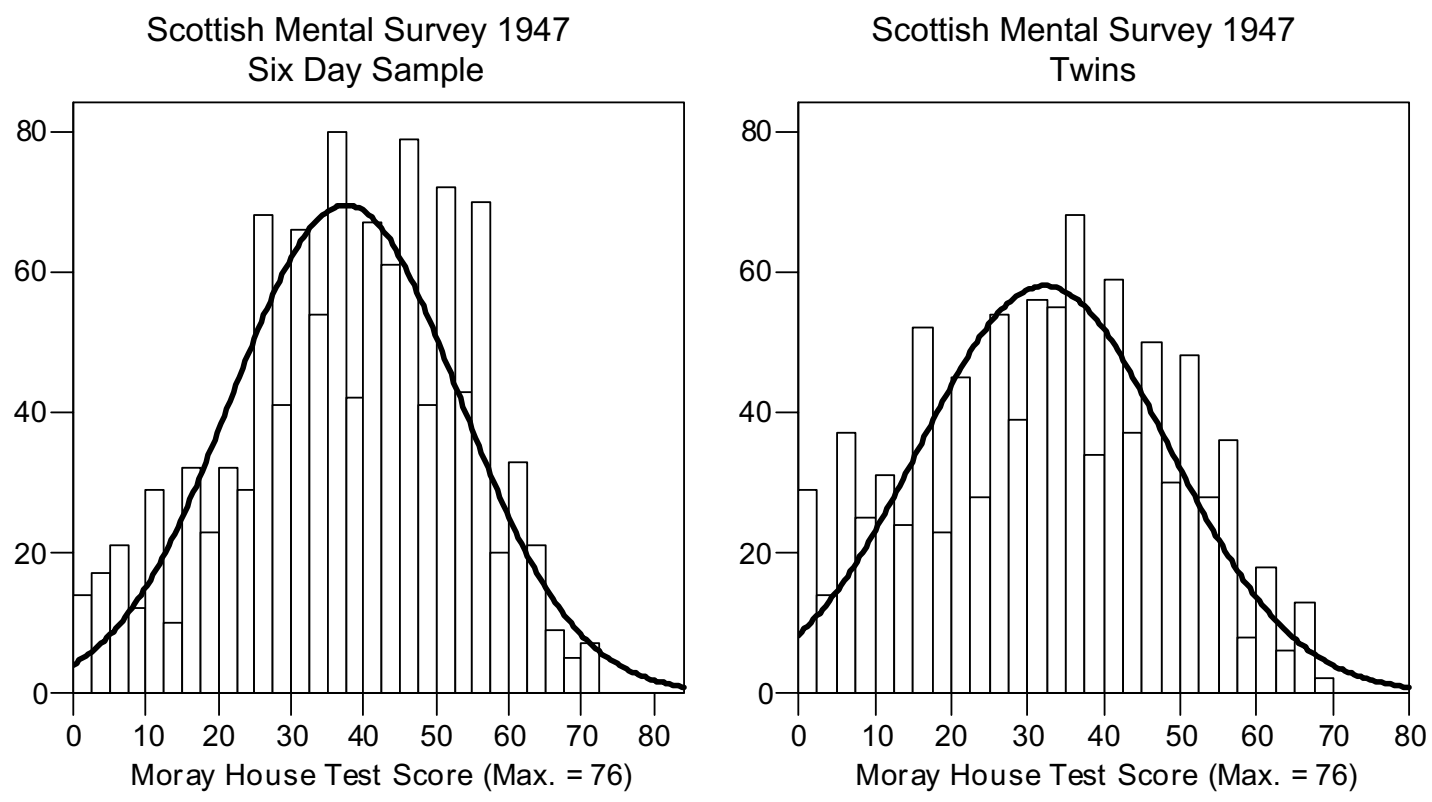

Figure 2

Distributions (with normal curve added) of Moray House Test (MHT) scores for the 6-day sample (left panel) and twins (right panel) in the Scottish Mental Survey 1947.

Including all these effects reduced the effect of group (twin vs. 6-day sample) to a mean difference $=3.5$ MHT points, though it remained significant $(p<.001$, $\left.\eta^{2}=.014\right)$. To investigate the influence of each covariate on the effect of group (twin or 6-day sample) on MHT score, they were entered singly alongside the fixed effects of sex and father's occupational social class in a series of reduced models. The results show that the largest reductions in twin-singleton MHT score difference were for height and number of people in immediate family, which reduced the group difference to 4.6 and 3.9 points, respectively (Table 3). Again, because scores from members of twin pairs are nonindependent, the general linear modeling was rerun after randomly selecting just one member from each twin pair. The results were very similar to those using the whole twin sample (results not shown but available from the authors).

\section{$\overline{\text { Discussion }}$}

The results of these two population-wide studies agree closely. For people in Scotland whose age was about 11 years in 1932 or 1947, being a member of a twin pair was associated with an IQ deficit of about a third of a standard deviation; that is, about 5 IQ points in the typical IQ scale with $S D=15$. The results are similar to those found by Record et al. (1970) that were based on subjects born in the early 1950s. Given the predictive value of mental ability tests for educational, occupational and health outcomes, this must be considered a substantially important effect at the population level. The twin disadvantage was not caused by differences in social background, as assessed by father's occupation.

The study by Posthuma et al. (2000) found no clear evidence of a twin decrement in the mental abilities of adult twins born between the 1950s and the 1970s approximately, despite having high power. The study might perhaps include families from especially healthy twins. A strength of the Posthuma (2000) study was that twins and singletons were from the same families, which affords within-family comparisons. It was a weakness of the present study that the twins and singletons were from different families. Another study which had the advantage of withinfamily comparisons of twins and their singleton siblings is the Twins Early Development Study (TEDS; Koeppen-Schomerus et al., 2003). The assessments were made at 2 and 3 years of age. There was no difference between twins and singleton siblings on general cognitive ability, but singletons scored higher on nonverbal cognitive ability.

The doubts raised by Posthuma et al. (2000) were based upon two possible problems with prior work: selection bias and possible differences in the social background of the twins' families. Our analyses of the Scottish Mental Surveys' twins indicate that the previously suggested 5-point mean deficit in the IQs of twins persists, at least at age 11 years, when neither of these factors is a likely problem. One hypothesis, which was suggested by Posthuma et al. and is consistent with most data, is that there might be a twin-singleton ability difference that persists to adolescence but disappears by adulthood. 


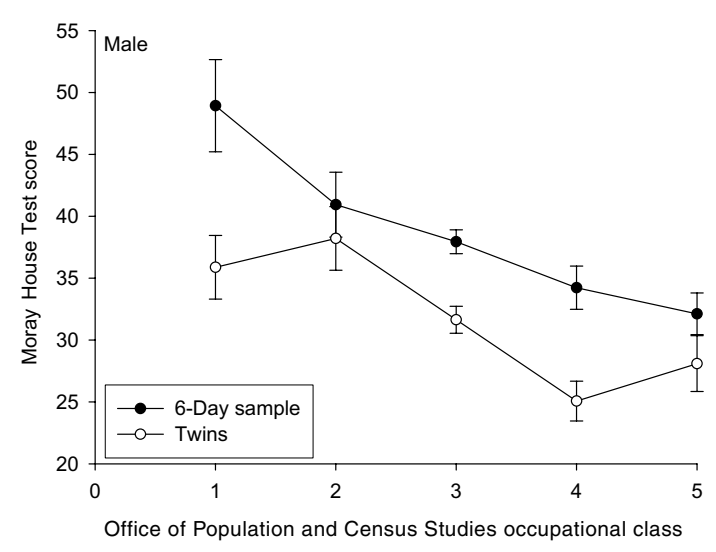

Figure 3

Moray House Test (MHT) scores (and standard errors) separated by father's occupational class of male twins and male singletons from the Scottish Mental Survey 1947.

Singletons are nontwin members of the 6-day sample.

What are possible causes of the replicated twin decrement in mental ability found here? Background family factors and educational attendance did not alter the effect. There was no evidence to support the suggestion that the twin-singleton difference was greater among less professional social classes (Alin Akerman \& Fischbein, 1991, p. 30). Height had a small effect. The number in the family reduced the effect, but this factor is known to be a correlate of mental ability test score anyway (Deary et al., 2004; Scottish Council for Research in Education, 1949, 1953). Possibly the difference in mental ability is caused by having two growing beings sharing one womb, and the limitations on the quality of the intrauterine environment imposed by this. It would be interesting to quantify twin-twin differences in the quality of intrauterine environment and correlate this with mental ability discordances between twin pairs. One possible indicator might be birthweight, which was found to be associated with twin score decrements in some twin studies (Alin Akerman \& Fischbein, 1991; Record et al., 1970). Twins have a smaller birthweight, and birthweight is related to intelligence test scores in childhood (Boomsma, 2000). There is some indication that birthweight discordances correlate with childhood mental ability differences in dizygotic (DZ) twin pairs, but less so among monozygotic (MZ) twins (Shenkin et al., 2004). The sample size is small, and larger studies are needed to test this further.

There is unsettled debate about whether twins raised as singletons lose any twin disadvantage in ability test scores. In the Collaborative Perinatal Project of the United States, twins raised as singletons scored at the same level as twins, suggesting a prenatal origin to their lower mental scores (Myrianthopoulos

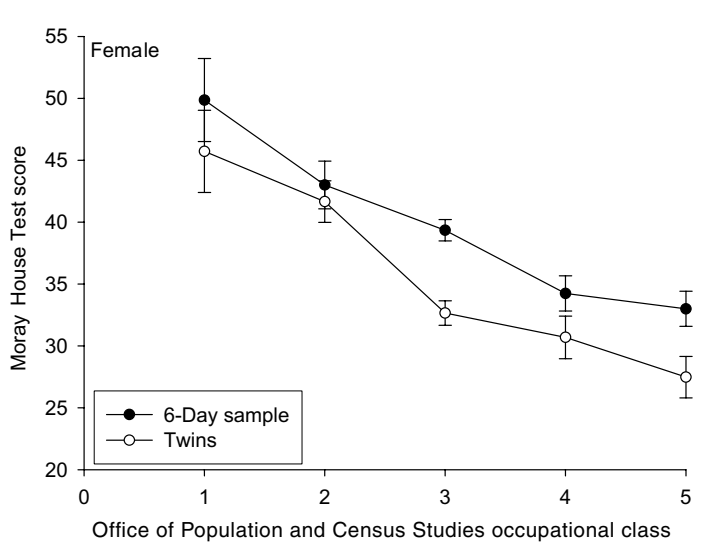

Figure 4

Moray House Test (MHT) scores (and standard errors) separated by father's occupational class of female twins and female singletons from the Scottish Mental Survey 1947.

Singletons are nontwin members of the 6-day sample.

et al., 1976). On the other hand, the Birmingham, United Kingdom, study found that in cases where one twin was stillborn or died in the first 4 weeks of life, surviving twins scored almost at singleton levels (Record et al., 1970). They concluded that 'the large differences in weight and duration of gestation between single and multiple births do not result in appreciable score differences' (p. 19). Neither did they find the twin deficit to be due to maternal age, birth order, monozygosity or delivery order; instead they suggest that the cause is 'frequent contact between twin and co-twin, and reduced opportunities for verbal communication with adults and older sibs' (p. 19).

There are possible limitations to the present study. The population data were not absolutely complete, though it is unlikely to be bettered, and any selection bias effects would be negligible. The data are from older cohorts and it may not be assumed that the twin-singleton mental ability difference occurs with the same effect size in later cohorts, or in different geographical populations. It is important, though, to know whether any twin-singleton mental ability difference existed at different times, which could give a clue to possible causes. A database-matching method (of surname, date of birth and school) was used for identifying twins in SMS1932; twins were not explicitly recorded in the survey's records. However, the 1932 twin rate proved similar to that found in 1947, perhaps with slightly less survival in 1921-born twins. Another possible reason for an apparently slightly greater proportion of twins in 1947 was that twin birth records from 1939 onwards in Scotland included stillbirths. That is, from 1939 onwards, if one live birth was born from a twin pregnancy the person was recorded as a twin. Prior to 1939, the single live birth from a twin 
Table 3

General Linear Modeling of Moray House Test (MHT) Scores in Twins Versus 6-day Sample Subjects From the Scottish Mental Survey of 1947

\begin{tabular}{|c|c|c|}
\hline $\begin{array}{l}\text { Effect of variable } \\
\text { in full model } F_{1} p, \eta^{2}\end{array}$ & $\begin{array}{l}\text { Effect in reduced modelt with only } \\
\text { group, sex and social class: } F, p, \eta^{2}\end{array}$ & $\begin{array}{c}\text { Group (twin vs. 6-day sample) } \\
\text { MHT difference in reduced } \\
\text { model }^{\ddagger}\end{array}$ \\
\hline
\end{tabular}

\begin{tabular}{lrrr}
\hline Fixed effects & & & 5.7 \\
Group: twin or singleton & $26.9,<.001, .014$ & $68.2,<.001, .033$ & - \\
Sex & $9.9, .002, .005$ & $6.0, .014, .003$ & - \\
Social class & $6.6,<.001, .014$ & $29.6,<.001, .056$ & 5.6 \\
\hline Covariates & & & 5.1 \\
Age at testing & $58.4,<.001, .030$ & $82.4,<.001, .039$ & 5.7 \\
Home occupancy index & $27.3,<.001, .014$ & $102.8,<.001, .050$ & 4.6 \\
School per cent attendance & $28.6,<.001, .015$ & $39.0,<.001, .019$ & 3.9 \\
Height & $65.8,<.001, .033$ & $150.2,<.001, .071$ & \\
Number in family & $63.8,<.001, .032$ & $148.0,<.001, .069$ & \\
\hline
\end{tabular}

Note: 'The full model includes all fixed effects and covariates in the first column.

tThe reduced model always includes the fixed effects of group (twin vs. 6-day sample), sex and social class, and examines the effect of each of the covariates in isolation.

‡Differences in estimated marginal means.

pregnancy was recorded as a singleton birth. The twin-whole population comparison of MHT scores in the SMS1932 dataset was done using the entire population dataset, including twins, but this would have a very small effect. There was no zygosity information on the twins, so the results apply to twins overall, and cannot be separated into effects on $\mathrm{MZ}$ and DZ twins. As the Scottish Mental Surveys examined single birth years, there was no possibility of examining singleton siblings of the twins.

The present study has a number of advantages. It was based on data from two whole-population surveys. The computerized SMS1932 resource gives a population mean (SD) MHT score of 33.9 (15.4). It compares well with the $34.46(15.4)$ recorded in the Survey monographs (Maxwell, 1961, p. 22). The resource lacks data from the few missing SMS1932 ledgers. It is the computerized resource that provided the twin and whole-population data, and so it provides the correct background population mean and standard deviation for MHT score. It was also advantageous to have a carefully collected, representative sample of the SMS1947 with extra variables. The mean (SD) MHT score of 6-day sample subjects was 37.5 (15.7), which compares well with the whole population results of 36.74 (16.1; Maxwell, 1961, p. 22). The MHT used in the SMS1932 and SMS1947 has good concurrent validity at age 11 and later in life, and shows high stability from age 11 to about age 80 (Deary et al., 2000, 2004). The two population surveys provided a replication of the twin deficit, 15 years apart, with similar effect sizes. A number of possible contributing factors was explored, especially father's occupation, education and home circumstances. In summary, the cognitive cost of being a twin, at least up until adolescence, is about 5 IQ points, or about one third of a standard deviation.

\section{$\overline{\text { Acknowledgments }}$}

We thank the Scottish Council for Research in Education for permission to use the data for these analyses. Ian Deary is the recipient of a Royal Society-Wolfson Research Merit Award that also supports Alison Pattie. Lawrence Whalley holds a Wellcome Trust Career Development Award.

\section{References}

Alin Akerman, B., \& Fischbein, S. (1991). Twins: Are they at risk? A longitudinal study of twins and nontwins from birth to 18 years of age. Acta Geneticae Medicae et Gemellologiae, 40, 29-40.

Boomsma, D. I. (2000). Genetics mediate relation of birth weight to childhood IQ. British Medical Journal, 323, 1427.

Breland, H. M. (1974). Birth order, family configuration, and verbal achievement. Child Development, 45, 1011-1019.

Deary, I. J., Whalley, L. J., Lemmon, H., Crawford, J. R., \& Starr, J. M. (2000). The stability of individual differences in mental ability from childhood to old age: Follow-up of the 1932 Scottish Mental Survey. Intelligence, 28, 49-55.

Deary, I. J., Whiteman, M. C., Starr, J. M., Whalley, L. J., \& Fox, H. C. (2004). The impact of childhood intelligence on later life: Following up the Scottish Mental Surveys of 1932 and 1947. Journal of Personality and Social Psychology, 86, 130-147.

Hart, C. L., Deary, I. J., Taylor, M. D., MacKinnon, P. L., Davey Smith, G., Whalley, L. J., Wilson, V., Hole, D. J., \& Starr, J. M. (2003). The Scottish Mental Survey 1932 linked to the Midspan studies: A prospective investigation of childhood intelligence and future health. Public Health, 117, 187-195. 
Hay, D. A., O’Brien, P. J., Johnston, C. J., \& Prior, M. (1984). The high incidence of reading disability in twin boys and its implications for genetic analyses. Acta Geneticae Medicae et Gemellologiae, 33, 223-236.

Koeppen-Schomerus, G., Spinath, F. M., \& Plomin, R. (2003). Twins and non-twin siblings: Different estimates of shared environmental influences in early childhood. Twin Research, 6, 97-105.

MacPherson, J. S. (1958). Eleven-year-olds grow up. London: University of London Press.

Maxwell, J. (1961). The level and trend of national intelligence. London: University of London Press.

Mehrotra, S. N., \& Maxwell, J. (1949). The intelligence of twins: A comparative study of eleven-year-old twins. Population Studies, 3, 295-302.

Myrianthopoulos, N. C., Nichols, P. L., \& Broman, S. H. (1976). Intellectual development of twins: Comparison with singletons. Acta Geneticae Medicae et Gemellologiae, 25, 376-380.

Nathan, M., \& Guttman, R. (1984). Similarities in test scores and profiles of Kibbutz twins and singletons. Acta Geneticae Medicae et Gemellologiae, 33, 213-218.
Posthuma, D., De Geus, E. J. C., Bleichrodt, N., \& Boomsma, D. I. (2000). Twin-singleton differences in intelligence? Twin Research, 3, 83-87.

Record, R. G., McKeown, T., \& Edwards, J. H. (1970). An investigation of the difference in measured intelligence between twins and single births. Annals of Human Genetics, 34, 11-20.

Registrar General for Scotland. (1921). Sixty-seventh annual report. Edinburgh, UK: Her Majesty's Stationery Office.

Scottish Council for Research in Education. (1933). The intelligence of Scottish children. London: University of London Press.

Scottish Council for Research in Education. (1949). The trend of Scottish intelligence. London: University of London Press.

Scottish Council for Research in Education. (1953). Social implications of the 1947 Scottish Mental Survey. London: University of London Press.

Shenkin, S. D., Starr, J. M., \& Deary, I. J. (2004). Birth weight and cognitive ability in childhood: A systematic review. Psychological Bulletin, 130, 989-1013. 